\title{
LA QUERELLA DE LAS COSAS MARX, LUCRECIO Y EL DESORDEN DEL MUNDO
}

\author{
The Quarrel of Things. Marx, Lucretius, and the Anarchy of the World
}

\author{
Sergio Villalobos-Ruminott \\ Universidad de Michigan \\ svillal@umich.edu
}

\begin{abstract}
Resumen:
A partir de una lectura centrada en On the Nature of Marx's Things. Translation as Necrophilology, el siguiente artículo intenta situar la lectura de Marx desarrollada por su autor, Jacques Lezra, tanto en el contexto de sus demás contribuciones relativas a un materialismo salvaje, como en el contexto de los actuales debates sobre nuevos materialismos y ontologías orientadas al objeto. La referencia lucreciana de Lezra permite activar lo que Althusser llamó una corriente subterránea de materialismo aleatorio, cuestión que no sólo problematiza el materialismo histórico convencional, sino la dialéctica materialista y su origen hegeliano. En efecto, subyace tanto a su libro sobre Marx, como a sus demás monografías una lectura fuerte de Lucrecio y su De Rerum Natura, cuestión clave para comprender la singularidad de sus aproximaciones al problema de la traducción, de la mercancía, de la filología negativa y, sobre todo, de un republicanismo no normativo ni soberanista, constituido por instituciones defectivas y abiertas.
\end{abstract}

\section{Palabras clave:}

Atomismo, Materialismo Aleatorio, Necrofilología, Republicanismo, Marxismo.

\begin{abstract}
:
Starting by a focused reading of Jacques Lezra's On the Nature of Marx's Things. Translation as Necrophilology, the following piece attempts a double conceptualization, first related to the place of this book within Lezra's contributions, and then, related to his timely reading of Marx in the context of current debates about new materialisms and object-oriented ontologies. To do so, we try to clarify the reference to Lucrecio and De Rerum Natura, as this reference explains the singular character of Lezra's reading of Marx, his problematization of both historical and dialectical materialism, and his reactivation of Althusser's so-called "underground current of the materialism of the encounter". Actually, Lezra's reading of Lucrecio is crucial to understand his singular approach to republicanism from a non-normative and materialist perspective, able to problematize the conventional notion of sovereignty while proposing a new theory of defective institutions at odds with the liberal and normative traditions.
\end{abstract}




\section{Keywords:}

Atomism, Random Materialism, Necrophilology, Republicanism, Marxism.

Recibido: 25/05/2020

Aceptado: 30/06/2020

Lo que Lucrecio reprocha a los predecesores de Epicuro es haber creído en el Ser, en el Uno y en el Todo. Estos conceptos son las manías del espíritu, las formas especulativas de la creencia en el fatum, las formas teológicas de una falsa filosofía.

Gilles Deleuze, Lógica del sentido.

I.

Considérense las siguientes anotaciones como un intento preliminar de aproximación al trabajo crítico y teórico desarrollado, en los últimos años, por Jacques Lezra. En esta aproximación hablaré de muchas cosas, de una variedad de ellas, empezando por una famosa mesa, la mesa de Marx, la mesa que funciona como ejemplo central del fetichismo de la mercancía, su valoración, su inscripción en la teoría del valor, en el sistema capitalista; pero también hablaré de otra mesa, imaginal, una que escapa a las ponderaciones de la valoración y a la imagen de la mercancía y que interrumpe la conversión, la traducción casi automática, entre objeto y nombre, entre la cosa y su concepto. Hablaré de la o las mesas de Marx, de cómo ellas permiten las atentas observaciones elaboradas por Lezra en su reciente intervención titulada Sobre la naturaleza de las cosas de Marx (2018) ${ }^{1}$, y de cómo dichas observaciones, convertidas en proposiciones, resultan, a su vez, difíciles de convertir en un relato unificado, pues interrumpen la lectura convencional de la lógica de la mercancía, es decir, interrumpen la recepción habitual de Marx y "su" Ilamado materialismo dialéctico, para posibilitar un materialismo de otro tipo, uno para el cual el poeta romano Tito Lucrecio Caro, resultará crucial. Materialismo, in-traductibilidad y necrofilología entonces, marcarán nuestra ruta.

Por supuesto, no pretendo agotar, sintetizar o abarcar la serie de sutiles desplazamientos que hacen posible esta lectura lucreciana de Marx, sino habitar en ella, tendiendo relaciones con lo que pareciera ser la propuesta general de Lezra, relativa a un republicanismo salvaje, ajeno a las prescripciones normativas y jurídicas de la

${ }^{1}$ También podríamos traducirlo como De la naturaleza de las cosas de Marx. La traducción como necrofilología. 
tradición, y ajeno a las fundamentaciones éticas u ontológicas del orden social. La mayor dificultad que confrontamos tiene que ver, sin embargo, con el habitus escritural de Lezra, quien lejos de identificarse como filósofo profesional o como crítico literario, se resiste a la operación del sentido, a su lógica, interrumpiendo la traducción como equivalencia, para habitar en las oraciones, en las palabras, al modo de un filólogo melancólico o un cabalista heterodoxo, para quien la forma, el sonido y la organización de las letras parecieran contener el secreto del universo. Esa melancolía proviene de haber percibido en el mundo sus múltiples posibilidades, es decir, de haber entendido cómo todo aquello que se nos presenta de manera natural y necesaria no es sino el producto de una serie de contingencias radicales.

Me parece que esta referencia borgeana no es del todo descaminada, pues es en los relatos de Borges donde el nominalismo radical de Funes el memorioso, la inverosímil enciclopedia china titulada Emporio celestial de conocimientos benévolos, o el imposible idioma analítico de John Wilkins se muestran como interrupción del acto mismo de pensar. Pensar, habría que precisar, en sentido platónico; es decir, a partir de la sistematización, la unificación, la esquematización y la síntesis; esto es, a partir de la abstracción. De hecho, insiste Borges, "[Funes] Había aprendido sin esfuerzo el inglés, el francés, el portugués, el latín. Sospecho, sin embargo, que no era muy capaz de pensar. Pensar es olvidar diferencias, es generalizar, es abstraer. En el abarrotado mundo de Funes no había sino detalles, casi inmediatos" (Borges, 1994: 490). Por supuesto, el caso de Funes no es solo el de una memoria infinita, sino también el de una sensibilidad hipertrofiada y dislocada, y es esta dislocación de los sentidos la que le permite experimentar las infinitas variaciones de un objeto, sentir el paso de los segundos, ver la decadencia de la carne en su imagen en el espejo. Es como si Funes experimentara lo real a partir de una insubordinación de los sentidos, los que se rebelan de la facultad de juzgar y se amotinan contra el entendimiento, siempre armado de esquemas y conceptos, para insistir en la singularidad, casi imperceptible, de las cosas y sus modos de ser.

Exagero un poco con esta ilustración, pero no tanto, pues el horizonte en el que se inscribe el trabajo de Lezra está marcado por una cierta convergencia, todavía a ser iluminada, entre nominalismo, atomismo y materialismo. Cada uno de estos términos comporta, a su vez, una complicación mayor, no tanto por la historia conflictiva de sus recepciones, sino por la forma novedosa en que el trabajo de Lezra hace uso de ellos para despejar un problema mayor, a saber, la posibilidad de una "ontología" no atributiva ni unificante que permita la configuración de un republicanismo material capaz de "traducir", siempre precaria o defectivamente, las claves de una cosmología y de una física plural y heteróclita a las coordenadas de una política institucional sin arché ni centro. Como se ve, una tal ontología de lo múltiple, que no se piensa de manera jerárquica ni atributiva, está lejos de la misma ontología, de lo que uno asume, convencional y naturalmente, como ontología, lo que nos presenta un primer problema: ¿Qué le pasa a la ontología con la inflexión lucreciana de Lezra? Problema al que se le suma otro igualmente delicado: Sin ontología jerárquica ni atributiva ¿Cómo pensar la traducción y/o la traslación desde esta "física o cosmología de las pasiones", -a la que Deleuze denomina como "un naturalismo radical"- en su paso hacia el orden sin fundamento de una república de los seres vivos, que no esté afirmada en la ficción unificante del contrato o de la soberanía? ¿Qué papel juega 
aquí el clinamen como anulación de todo determinismo?, entendiendo el clinamen como movimiento mínimo e indeterminado, del que surge la cuestión de la contingencia $^{2}$. Es más, gracias a todos estos desplazamientos, ¿cómo podemos pensar ahora la diferencia entre la noción aristotélica de accidente y la noción lucreciana de contingencia, de una contingencia más radical que aquella pensada modernamente en el pragmatismo de Rorty, la teoría de sistemas de Luhmann o la teoría de la hegemonía de Laclau y Mouffe? ¿Qué es, finalmente, un acontecimiento cuya contingencia no responde a ninguna lógica de la necesidad, ni para afirmarla ni para negarla, y cuya inscripción precipita en lo real, descentrando su pretendida unidad?

Quisiera decirlo de manera muy clara: Lezra no elabora una teoría en sentido convencional, y aunque es posible rastrear la coherencia de su proyecto en la trilogía compuesta por sus ya publicados volúmenes Wild Materialism y On the Nature of Marx's Things, los que serían continuados por un "último" libro, aparentemente titulado Defective Institutions. A Protocol for the Republic ${ }^{3}$, aún así, me resulta difícil contraponer a la operación de substracción, de interrupción, de separación que prima en sus textos, la lógica contrapuesta de narrativización, de continuidad y de producción de un verosímil o "imagen del pensamiento" característica de las formas de proceder de la filosofía y de la teoría universitaria. En lo que sigue intento, no sin problemas, comentar su lectura de Marx en el contexto de la crítica al materialismo vulgar, el predominio naturalizado de una cierta tradición onto-teológica que encontraría en el hegelianismo (que no es lo mismo que en Hegel) una encarnación fundamental. A partir de allí, intento mostrar la continuidad entre sus observaciones epistemológicas y políticas, para, en un tercer y último momento, inscribir esta lectura de Marx en el contexto general de su problematización de la violencia, la que resulta singularmente apropiada para pensar en un republicanismo material no atado a las determinantes normativas de un sujeto ético trascendental.

II.

Permítanme, a modo de excusa, referir el curso de 1964-65 de Derrida, titulado Heidegger, la cuestión del ser y la historia (Derrida, 2013; cf. versión inglesa: Derrida, 2016). En él, tempranamente Derrida acomete una lectura rigurosa de Ser y tiempo, a partir de destacar dos cuestiones centrales: su problematización de los límites ontoteológicos de la metafísica contemporánea para pensar la historicidad, y las formas en que la destrucción heideggeriana de la metafísica, entendida como destrucción de esas limitaciones, abre la pregunta por la historicidad; pero sin lograr escapar a ciertos remanentes onto-teológicos implícitos no solo en el lenguaje utilizado por Heidegger, sino en su problemática formulación relativa a la analítica existencial y la relación, cuasi autárquica (diríamos soberana) del Dasein con la finitud y la muerte, como

\footnotetext{
2 "Por eso afirma con razón Lucrecio que la desviación quiebra las fati foedera (los pactos del destino), y como él aplica en seguida esto a la conciencia, se puede decir del átomo que la desviación [clinamen o declinación] es ese algo en su interior que puede luchar y resistir" (Marx, 1971: 38).

${ }^{3}$ Cf. Lezra, 2010; versión española: Lezra, 2012. Habría que considerar también la reciente publicación sumaria de su República salvaje. De la naturaleza de las cosas (Lezra, 2020).
} 
índice de una nueva concepción de la autenticidad de la existencia. Lo que Derrida entiende como una solicitación del pensamiento heideggeriano le lleva, por un lado, a reconocer la pertinencia de la destrucción emprendida por el alemán de aquello que aparece como una historicidad siempre anclada al privilegio de un etnocentrismo espiritual que se presentaría bajo las formas de la consciencia, la razón, el saber y la ciencia (Hegel, Husserl, etc.). Imposibilitados de ir más allá de esta curiosa autoreferencialidad, los pensadores modernos seguirían anclados a la onto-teología, cuya mayor o más clara y acabada formulación moderna se encontraría en el pensamiento hegeliano. En efecto, sería la lógica hegeliana, bajo la forma de un despliegue autotélico de la historia como movimiento de la razón hasta llegar a su misma realización, lo que nos impide entreverarnos con la historicidad de manera radical, pues esta historicidad estaría siempre ya anclada, hilvanada y leída desde la performance retroproyectiva de la razón, la que culmina, no por casualidad, en el Estado. De ahí se sigue, entonces, que Hegel nos hable de pueblos sin historia; Freud, de pueblos sin transferencia; y Husserl, de pueblos sin ciencia (sin un concepto espiritual de ciencia). Y no es menor esta vinculación entre historicidad y razón, de la que se sigue una vinculación aún más delicada entre ontología y política, una onto-política que el republicanismo material y lucreciano, como sugeriremos, no puede sino subvertir y anarquizar.

De este breve e injusto recuento, me interesa destacar dos aspectos útiles para entender mejor el aporte de Lezra. Por un lado, Derrida reconoce la radicalidad de la destrucción heideggeriana de la onto-teología, entendiendo dicha onto-teología como subsunción de la historicidad a la lógica de la existencia, cuestión que en Hegel, repito, habría adquirido su elaboración más acabada. ${ }^{4}$ Por otro lado, siguiendo meticulosamente el argumento heideggeriano, Derrida retoma las críticas heideggerianas a un cierto hegelianismo que todavía acecha a la concepción marxista de la historia, para mostrar cómo el mismo Heidegger no logra salir totalmente de la problemática de la onto-teología, a pesar de que su proyecto consiste, más allá de lo que él Ilama "el rumor público", en la destrucción de toda ontología. En efecto, insiste Derrida, lo que Heidegger intenta no es solo la reconfiguración de la ontología fundamental, como corrección de la ontología aristotélico-kantiana, la que habría predominado como metafísica desde el olvido de la pregunta por el ser; lo que Heidegger realmente intenta es, pues, la destrucción de la ontología, cualquiera sea esta, para abrirse totalmente a la cuestión de la historicidad, pero esa apertura ocurre siempre desde una condición dada, la del Dasein como Mitsein, es decir, como seren-el-mundo-con-otros, que Derrida no se cansa de problematizar. No es mi intención mostrar aquí la forma en que Derrida ha interrogado la cuestión del Dasein y su vecindad con el ser, solo me interesa dejarlo consignado.

Antes, sin embargo, de dirigirnos a nuestra segunda cuestión, toda ella relacionada con la problemática de la différance y con la posibilidad de deponer el vínculo, ontoteológico y onto-político, entre lógica y existencia, es decir, entre republicanismo y

\footnotetext{
${ }^{4}$ No olvidemos que Lógica del sentido de Deleuze es un directo homenaje a Jean Hyppolite, su profesor, y autor del notable libro dedicado a la lógica hegeliana Lógica y existencia (Hypolitte, 1996).
} 
soberanía (indivisible o unitaria), permítaseme volver a la anterior, a saber, la lectura derridiana de la acusación de Heidegger relativa a un cierto hegelianismo que acecharía a Marx y al marxismo. En efecto, es en la sesión dos, del 30 de noviembre de 1964, donde Derrida comienza a dar cuenta de la problemática concepción de la historia elaborada por Marx y de la vacilante lectura de esta concepción realizada por Heidegger. Recurriendo a la Carta sobre el humanismo, Derrida nos recuerda ese famoso y ambiguo comentario en el que Heidegger nos dice: "Es precisamente porque al experimentar el extrañamiento Marx se adentra en una dimensión esencial de la historia por lo que la consideración marxista de la historia es superior al resto de las historias" (Heidegger, 2013: 57). Por supuesto, dicho extrañamiento, que en Marx está pensado en términos de una compleja teoría del trabajo enajenado, en Heidegger adquiere un cierto carácter "ontológico" relativo al extravío del habitar en el horizonte de la técnica, o si se prefiere, del olvido de la pregunta por el ser y predominio de una relación instrumental con el sentido y el mundo. Continúa Heidegger: "Pero como ni Husserl ni como yo veo hasta ahora, tampoco Sartre reconoce la esencialidad de lo histórico en el ser, por eso, ni la fenomenología ni el existencialismo llegan a esa dimensión en la que resultaría posible por primera vez un diálogo productivo con el marxismo" (Heidegger, 2013: 57-8, cursivas mías). Por supuesto, Heidegger no prosigue con ese diálogo, sino que inmediatamente pasa a mostrarnos sus reservas:

Claro que para eso también es necesario liberarse de las representaciones ingenuas que se suelen tener del materialismo, así como también de las críticas baratas que se le suelen echar en cara. La esencia del materialismo no consiste en la afirmación de que todo es materia, sino, más bien, en una determinación metafísica según la cual todo aparece como material de trabajo (58).

Esta vinculación, fundamental para todos los casos, entre materialismo y trabajo (labor / trabajo vivo) sería la que limita al materialismo marxista, siempre que "la concepción metafísica moderna de la esencia del trabajo ha sido pensada ya con antelación en la Fenomenología del espíritu de Hegel como el proceso que se dispone así mismo de la producción incondicionada, es decir, como objetivación de lo efectivamente real por parte del hombre, experimentado este como subjetividad" (58). En cuyo caso, la concepción marxista de la praxis y del quehacer humano contendría las determinantes de este concepto de trabajo o labor que entiende el mundo como efecto de una actividad de objetivación y re-conciliación o re-subjetivación de lo previamente objetivado. De ahí que Heidegger insista: "la esencia del materialismo se oculta en la esencia de la técnica, de la que se escribe mucho y se piensa poco" (2013: 58; cf. Derrida, 2013: 45ss).

No me interesa ahora dirimir si Heidegger tiene razón, o si Derrida retoma esta cuestión más allá del uso ilustrativo al que sirve en estas sesiones. Lo que me interesa de acá es el problema mismo: ¿hasta qué punto el materialismo de Marx es homologable o, para decirlo en términos heideggerianos, está determinado por la esencia de la técnica, que consiste en la determinación del trabajo, of the labor, como un movimiento circular de objetivación y re-subjetivación? Por supuesto, siempre se puede objetar la lectura heideggeriana de Hegel y mostrar que su Lógica supone una relación compleja con el mundo material y orgánico cuyo catalizador no es solo el trabajo. $Y$ también podemos insistir en mostrar al mismo Derrida pre-ocupado desde 
siempre con esta problemática, no solo para responder a Heidegger o defender a Marx, cuestión menor, sino para seguir interrogando las determinaciones de la lógica hegeliana en la configuración logocéntrica del sentido, de la política, de la familia, de la vida y de la muerte, y por supuesto, de la determinación soberana de la democracia. De esto da cuenta una inabarcable cantidad de monografías, ensayos, artículos e intervenciones dedicadas a mostrar las habilidades del filosofo argelino y su relativa cercanía con el materialismo antiguo, con Althusser y, de paso, con la corriente subterránea de un materialismo aleatorio que ha llegado a ser un nombre más o menos común para un campo marxista de análisis al que el mismo Lezra podría pertenecer fácilmente. ${ }^{5}$

Incluso, no lejos de toda esta argumentación, está la sostenida solicitación derridiana de la lógica hegeliana en el discurso de la biología contemporánea, particularmente en los nombres de François Jacob y Georges Canghilhem (Derrida, 2019), cuestión que vuelve a poner en el centro de la discusión las determinantes materiales de la existencia, más allá de la analítica heideggeriana y del discurso hegeliano sobre la vida orgánica y su relación con el concepto, haciendo vacilar, una vez más, las fronteras que pretendían dividir al hombre del animal y a la materia orgánica de la inorgánica. Todo esto resulta relevante, claro está, para pensar lo que Lezra nos quiere decir con su lectura de Marx.

III.

Pero, insisto, más allá de todo esto, ¿hasta qué punto está Marx (y el marxismo) atrapado en las determinaciones de una formulación especulativa o dialéctica del materialismo? Para responder a esto, necesito volver a la mesa de Marx, aquella que le sirve a Lezra para interrumpir la recepción habitual del alemán y de su materialismo dialéctico, y pensar desde lo que Lezra hábilmente Ilama una necrofilología, cuyo objetivo no es la producción de positividades, sino su interrupción. En efecto, Lezra vuelve a poner el acento en la relación (y la palabra relación no puede ser reducida a la de mediación dialéctica) entre palabras, cosas y objetos, pero no para restituir una unidad perdida, alojada en la postulación de una subjetividad capaz de mediar o fundamentar la relación, ni tampoco para ceder ante la oferta de una ontología matemática que recuperaría el proyecto de una lógica pluralizada (una Lógica de los mundos, à la Badiou), sino para abrir la cuestión misma del sentido, gracias al trabajo de deposición ("deponer" es un verbo lezraciano o lezrrático) e interrupción de esta

\footnotetext{
${ }^{5}$ Cuestión señalada por el mismo Lezra en su libro On the Nature... (2018) y repasada por Vittorio Morfino en su prólogo al libro de Lezra. Respecto a la relación, abierta y relevante, entre Derrida, el materialismo antiguo y Althusser, véanse, como mínimo, el seminario Theory and Praxis (Derrida, 2018a), la entrevista con Michael Sprinter Política y amistad (2018b), Espectros de Marx (2012), etc. Y respecto al materialismo, por supuesto, "La farmacia de Platón" (en Derrida, 1975), "Mis chances" (en Derrida, 2017) y la entrevista con Kadhim Jihad "El materialismo no dialéctico" (Derrida, 1986). Todas estas, informalmente consignadas, como referencias conocidas en el campo de discusión. Por supuesto, la referencia central al materialismo aleatorio está en "Le courant souterrain du matérialisme de la rencontre" (Althusser, 1982: 553-594).
} 
necrofilología o filología negativa, hacia el abismo de una falta de lógica, es decir, el abismo de una existencia sin arché o principio de razón.

No se trata de un gesto meramente especulativo (aunque nunca hay algo así como lo meramente especulativo). Lezra arranca su reflexión desde Wall Street, es decir, desde los procesos tardomodernos de abstracción del capitalismo, virtualización de la experiencia y universalización de las equivalencias. Su pregunta es precisamente por las condiciones de posibilidad para un pensamiento radical, crítico o materialista, asumiendo la imposibilidad del materialismo ingenuo frente a la desmaterialización del mundo actual. No nos propone una lectura sistemática de un Marx alternativo, una lectura que, en la forma de una teoría, permitiría reactivar el corpus marxista para entender el presente. Lo suyo es de otra laya, se trata de una desarticulación radical de la lógica que habita y habilita la recepción del mismo Marx, para interrogarla desde un momento lucreciano anterior a los textos canonizados: sus series de notas y observaciones, a fines de los 1830s, las que iban a ser fundamentales en su ya citada tesis doctoral, publicada en 1841 (Marx, 1971). Ahí, Lezra ve una vacilación que, en términos lucrecianos (y benjaminianos), podría ser pensada bajo la figura de una iluminación profana; lo que dicha iluminación profana ilumina, justamente, es una suspensión del clásico relato marxista sobre el modo de producción capitalista, la secuencia evolutiva de su despliegue y los vicios hegelianos de su universalismo, y muestra la posibilidad de una nueva relación epistemológica con el materialismo marxista, ya no mediada por la restitución (idealista) de una subjetividad dueña del proceso histórico y su sentido, sino abierta a la cuestión radical del clinamen como contingencia radical en la que descansaría una teoría todavía no pensada de la libertad.

Lo que resulta Ilamativo de este intento anti-lukacsiano, en rigor, es que no intenta mostrarnos, como lo hizo Althusser, un Marx no hegeliano surgido de un cierto corte epistemológico de dudosa datación (hacia 1845 o mediados de los 50s), ni intenta desechar el Ilamado Marx humanista de juventud, en el que las deformaciones feuerbachianas de Hegel dan paso a un pan-humanismo utópico y rebelde ${ }^{6}$. Antes bien, Lezra abre la firma-Marx, más allá de su resonancia habitual, hacia una serie de posibles encuentros que se ven posibilitados, a su vez, por la deposición operada por su filología negativa. Gracias a esta filología negativa o necrofilología, podemos leer el impacto del materialismo clásico, Epicuro y Lucrecio, no solo en la tesis de 1841,

\footnotetext{
${ }^{6}$ Pienso acá en el notable ejercicio desplegado por Felipe Martínez Marzoa en su La filosofía de "El capital" (2018), originalmente publicado en 1983. Libro que, buscando prevenir los excesos historicistas del materialismo histórico, postula a El capital como una ontología de la sociedad moderna, cuestión que, a primera vista, podría resultar contraproducente, a menos, claro, que estemos dispuesto a asumir el carácter específico de esa ontología diseñada conceptualmente por Marx en su obra mayor. Lo que Martínez Marzoa consigue no es solo dirimir la polémica althusseriana contra el historicismo, sino aplacar las demandas contemporáneas contra un cierto etnocentrismo marxista y contra las limitaciones empíricas de El capital, mediante la conversión de dicho libro no en una analítica histórico-social, un modelo ideal á la Weber o una obra histórica mayor, sino en una obra filosófica sobre el mundo moderno. Dejo insinuado acá ese posible contraste entre el Marx de Lezra y el de Martínez Marzoa, que se me antoja importantísimo.
} 
sino en El capital. La necrofilología, de alguna manera anticipada intempestivamente por Nietzsche ("Wir Philologen"), suspende la producción de positividades (Foucault) y continuidades, permitiéndonos interrogar las mismas condiciones de la recepción ya no según la historia vulgar de los textos y sus lecturas, sino mediante dislocaciones que enrevesan el sentido común de los textos, para ver en ellos, ya no una economía organizada de fuerzas y significaciones hegemonizadas según un orden principial y epocalmente distinguible (epocal en sentido de Reiner Schürmann (cf. 2017) o epistémico en sentido foucaultiano). Gracias a esta anarquía (sin arché o arjé) que habita en el corazón del pensamiento, se obliteran todas las economías de clasificación, ordenación y recepción, dejándonos, sin Dios ni ley, confrontados con la materialidad de los enunciados.

Esta necrofilología, pariente cercana de la lógica de la descomposición con la que Adorno interrumpe la buena nueva de la dialéctica hegeliana para hacerse cargo de la catástrofe instalada en el centro de la historia (cf. Adorno, 2005), supone entonces una cierta acentuación del proyecto de la historia conceptual, en la medida en que, mostrando la historicidad radical del sentido y del vínculo entre palabras, cosas y objetos, no puede sino tantear el sentido a partir de la postulación de conceptos defectivos: para-conceptos que, como prótesis, resultan ser simulacros y artificios que viven o habitan más allá de las pretensiones de autenticidad o trascendencia propias de la epistemología platónica. ${ }^{7}$ La necrofilología, por último, no lo olvidemos, supone una compleja teoría de la traducción, o de su imposibilidad, mostrándonos el sentido del mundo como compositum contingente, como chance o aleatoriedad, que escapa a la pretensión de una necesidad o de una causalidad dada por una teoría vinculante y universal (ya Epicuro y Lucrecio descreen de Demócrito y de la física clásica, que insiste en esa causalidad para evitar el vacío).

En efecto, esta concepción de la traducción supone una crítica de la teoría general de la equivalencia desarrollada por Marx en los Grundrisse y convertida en principio de articulación metafísica-epocal por Jean-Luc Nancy (Nancy, 2009; cf. VillalobosRuminott, 2015). Esto último no es secundario, la crítica de la equivalencia interrumpe las concepciones técnicas del lenguaje y la traducción, haciendo imposible alojar el trabajo de Lezra en lo que apresuradamente se denomina el giro lingüístico, y permiten mirar con cierta sospecha las reivindicaciones de los llamados nuevos materialismos y las ontologías orientadas al objeto (OOO), que se opondrían a Lezra por seguir alojando su operación crítica en el lenguaje, como si el lenguaje mismo no fuera lo que queda atomizado por la necrofilología. ${ }^{8} \mathrm{Y}$ habría que enfatizar el impacto de esta necrofilología como interrupción de la equivalencia y la traducibilidad universitaria, curricular, editorializada, pero también como interrupción de la misma

\footnotetext{
${ }^{7}$ Remito a la lectura deleuziana de los simulacros y a la forma en que se cita allí "La farmacia de Platón" de Derrida. Véase "Simulacro y filosofía antigua" (Deleuze, 1989: 268).

${ }^{8}$ Más allá de la serie de textos sobre la cuestión de la literatura comparada, de la historia conceptual, de la traducción, y su participación en el monumental volumen de Bárbara Cassin, Dictionary of the Untranslatables (Cassin et al, 2014), permítaseme referir un libro que demanda mayor tiempo y atención: Untranslating Machines. A Genealogy for the Ends of Global Thought (Lezra, 2017).
} 
equivalencia entre lenguaje qua logos (legein) y ser, pues esa equivalencia, clave de la ontología, no puede tolerar ni el clinamen ni la contingencia, ni la différance ni la historicidad, sin subordinarlas a una determinada reducción logocéntrica del ser y del sentido del mundo. A la vez, desde este materialismo atómico, si así pudiésemos Ilamarlo, los nuevos materialismos y las $\mathrm{OOO}$ en realidad emergen como formas invertidas de un monoteísmo peligrosamente humanista, que no solo le transfiere las cualidades del Uno a la materia, sino que, invirtiendo la lógica hegeliana, piensan la historia como de-subjetivación activa. Ya se sabe, el dolor de la montaña, el internet de las cosas, la democracia de los objetos, etc.

Es aquí donde Lezra se detiene en la "dancing table", la mesa danzante que aparece en el fetichismo de la mercancía, tomo I de El capital, y, reparando en la traducción, en el error de la traducción, nos muestra la imposible sutura entre objetos y sentido, haciendo intervenir el mismo error de la traducción como despeje y corrección de las pretensiones por sentar, de una vez, el sentido de la mesa, de las cosas, del sentido mismo. Es decir, mediante la variación que ocurre desde el original alemán a la versión inglesa de Moore y Aveling, fijándose en el mismo comienzo de la oración ("Es ist sinnenklar" en alemán; "It is as clear as noon-day", en inglés confundiendo sinnenklar con sonnenklar-), Lezra muestra que toda traducción importa una actualización, y por tanto, no es ajena a la valoración, la que no se remite o reduce a una simple línea de fuerza, como la descrita por el marxismo clásico. Necrofilología y teoría del valor, entonces, abren el camino para una concepción de la plusvalía que está más allá de la intencionalidad de la acción y las determinaciones subjetivas del trabajo (labor), cuestión que nos devuelve a la pregunta heideggeriana por la posibilidad de un materialismo más allá de la determinación hegeliana del trabajo como subjetivación. ¿Qué hacer de la historia que se acumula a nuestras espaldas, más allá de nuestros deseos?

En efecto, lo que aparece para Lezra en la traducción es la resonancia de una neutralidad que desvincula el valor de la intención, haciendo que la danza de la mesa, su devenir quimera, si atendemos a la versión en español, ya no remita a una equivalencia simple, sino que haga derivar el plusvalor hacia un registro de encuentros múltiples donde el objeto real, la cosa misma y la mesa se confunden con el concepto según una lógica del sentido que va más allá de los sentidos inmediatos con los que, eventualmente, determinaríamos las cualidades o atributos de la cosa que subyace a la mercancía. Así, tenemos por un lado la madera que hace a la mesa, luego está la 'mesa' misma que circula como mercancía; pero aparece ahí, bajo la apelación a la quimera, desde su condición inerte y apoyada, una tercera mesa, la "mesa" que ya no responde a la reciprocidad (o correlación) entre la cosa y su nombre. Lezra no lo dice así, pero se podría decir que el supuesto valor de uso es una postulación subjetivante que ya nunca más podrá ser devuelto al valor de la mercancía. Es esta tercera "mesa" que tiene sentido más allá del sentido y de los sentidos inmediatos, lo que complica, para Lezra, la resolución subjetivante o hegeliana, haciendo aparecer el plusvalor más allá de la misma intencionalidad del trabajo. Aquí el fragmento usado por Lezra en la versión de Siglo XXI:

Es de claridad meridiana que el hombre, mediante su actividad, altera las formas de las materias naturales de manera que le sean útiles. Se modifica 
la forma de la madera, por ejemplo, cuando con ella se hace una mesa. No obstante, la mesa sigue siendo madera, una cosa ordinaria, sensible. Pero no bien entra en escena como mercancía, se transmuta en cosa sensorialmente suprasensible. No solo se mantiene tiesa apoyando sus patas en el suelo, sino que se pone de cabeza delante de todas las demás mercancías y de su testa de palo brotan quimeras mucho más caprichosas que si, por libre determinación, se lanzara a bailar (Marx, 1975: 87).

Esa mesa que danza o que produce quimeras, a la que se adosa un sentido involuntario, incalculable o inesperado, un sentido que la traducción, involuntariamente, hace resaltar, es lo que termina por distinguir el trabajo de la necrofilología de la postulación de una Lógica de los mundos, que no puede renunciar a una restitución matemática de la unidad del ser. Y aquí es donde esta lectura de una obra madura, como suele decirse, tardía o acabada de Marx, como es El capital, nos muestra la preeminencia de una sospecha o de una suerte de insistencia subterránea en el alemán, relativa a un materialismo no dialéctico, que va más allá de la mera reconciliación o re-interiorización del objeto al sujeto, bajo la forma del reconocimiento. La mesa danzante no puede ser, inmediatamente y sin problemas, remitida al trabajo (labor) sin operar sobre esa traducción una asignación de sentido, una subjetivación que termina por ahogar la "mesa" en la 'mesa' y su madera.

¿Qué significa leer así a Marx? Y ya no solo a Marx, sino instalar esta necrofilología en el corazón de las humanidades contemporáneas, subsumidas a la lógica inmaterial de la universidad en ruinas (cf. Readings, 1997) y su equivalencialidad infinita. ¿Cómo pensar entonces la relación entre valoración, sentido y traducción desde una interrupción radical de los presupuestos naturalizados de la tradición, sus jerarquías y sus declaradas continuidades? ¿Qué rumbos debería tomar, por ejemplo, la literatura comparada si ha quedado meridianamente claro que la comparación misma estaba basada en un secreto trabajo del espíritu? He advertido que estas son notas preliminares, por lo tanto, no intentan ni hacer justicia (nunca se hace justicia) ni traducir o agotar lo que Lezra nos está diciendo, sino acusar recibo de su complejidad y relevancia. Y pensando en esa mesa multívoca y casi serial, danzante o danzarina, he recordado otra mesa de Marx, de la que habla un oscuro policía británico que, habiéndolo visitado en su morada, no pudo evitar describir, con dotes literarias, ese extraño objeto. Dice el reporte policial:

En toda la casa no se encuentra un mueble limpio y en buen estado; todo está estropeado, gastado, hecho añicos, todo está cubierto de una capa de polvo de un dedo de espesor, en todas partes reina el máximo desorden. En el centro del salón hay una gran mesa de edad respetable, recubierta de una espesa capa de cera jamás eliminada. Sobre ella se amontonan los manuscritos, los libros y los diarios de Marx, los juguetes de los niños, los remiendos de la mujer, tazas de té descantilladas, cucharas sucias, cuchillos, tenedores, candeleros, tinteros, vasos, pipas de terracota holandesas, ceniza de tabaco: todo arrojado desordenadamente sobre esa única mesa (cit. en Calasso, 1994: 275).

No habría que reconstruir la historia de cada uno de los objetos de esa mesa para adivinar que, sobre ella, Marx escribió no solo algunas páginas memorables de El capital, sino que en ella también se escenificó la danza inadvertida de un modo de 
ser de lo real que escapa a las determinaciones de la consciencia y a los deberes de la moral. El denunciado descuido y desorden que impera en la mesa es la imagen intempestiva de una catástrofe en medio de la cual se escribe la lógica sin lógica de nuestro mundo, y, como la catástrofe que estropea el jardín de Epicuro, la mesa de Marx nos habla de una proliferación para la que el materialismo monista, monoteísta, y furiosamente religioso no tiene antídoto (cf. Markovits, 1975). Las cosas se acumulan más allá de la intención, adquiriendo un derecho de ciudadanía en aquella mesa que figura la convergencia, sin necesidad, de los cuerpos en el espacio, forma de una república plebeya de desechos que escapan a la lógica del intercambio y de la comunicación.

\section{IV.}

Esa república salvaje de la que nos habla Lezra, me permite volver a la primera cuestión planteada en la lectura derridiana de Heidegger. A saber, la posibilidad, abierta gracias a una solicitación sin cuartel, de poner en cuestión la lógica hegeliana, expresión acabada y final de la onto-teología occidental, para plantear el problema de la historicidad, de la différance, de la democracia por venir y de la justicia, más allá de las determinaciones onto-políticas que se siguen del monoteísmo del uno, de las ontologías fuertes, del platonismo matemático y de las formas vinculantes del sentido y la traducción como equivalencia general. En efecto, la solicitación derridiana de las limitaciones de la analítica existencial, de la inadvertida metaforicidad heideggeriana y su sonambulismo, son continuadas por la interrogación de las pretensiones husserlianas por un origen incontaminado, que, a su vez, son seguidas por sus observaciones sobre la violencia metafísica de la ética como filosofía primera, y son retomadas en la larga interrogación de la soberanía indivisible de la tradición teológico-política occidental. Más que postular una imagen sistemática y acabada del pensamiento derridiano, me interesa destacar la relación casi orgánica entre sus tempranos cuestionamientos a Heidegger y su ineludible problematización de la democracia. Todo esto, abundantemente estudiado por el scholarship derridiano $^{9}$, lo menciono acá tan solo para decir que la consecuencia fundamental de la crítica de la ontología y su vinculación con la existencia es también la posibilidad de desvincular dicha ontología de la política, haciendo posible un pensamiento de la democracia que no esté fundado en lo que hemos Ilamado la onto-política occidental.

Por supuesto, este es para mí el otro lugar donde el trabajo de Lezra, dedicado a Marx o al materialismo de Lucrecio, a la república y sus instituciones defectivas, al terror y a la violencia, tiene algo importante que decir, en la medida en que co-incide con la deconstrucción en una consideración de la política desujetada de las determinantes ontológicas del ser y su soberanía. En efecto, ya habíamos planteado esta pregunta: ¿Qué le pasa a la ontología con la inflexión lucreciana de Lezra?

\footnotetext{
${ }^{9}$ No debe entenderse esto ni de manera peyorativa ni como una ironía; por el contrario, uso este nombre para aludir a un trabajo sostenido y necesario relativo a la problemática de la violencia y de la ley en Derrida y a sus relaciones con la democracia y la soberanía. Véase el instructivo texto de Campos Salvaterra. Violencia y fenomenología: Derrida, entre Husserl y Levinas (2017).
} 
¿Podemos seguir hablando, sin más, de ontología, y correr el riesgo de restituir un vínculo onto-político? ¿No es esta ontología plural de Lucrecio, como la llamó Deleuze, intrínsecamente politeísta y, por eso mismo, débil o defectiva en lo que respecta a las funciones de la fundación y de la fundamentación? Y sobre esto mismo, permítaseme otra pregunta derivada: ¿qué rol juega el poema, el poema de Lucrecio, en la misma constitución y como constitución de la república? ${ }^{10}$

Como se ve, la postulación de un republicanismo salvaje, materialista, ya no puede ser sostenido ni en la lógica del pensamiento normativo trascendental (Kant), ni en la lógica pacificadora de una resolución final de los conflictos (Hegel-Kojève). No se trata de una república "fundada" en el terror, sino de una república sin fundamento, agregada o compuesta en la experiencia insosegable del terror como vértigo de la existencia en el vacío. Ese republicanismo suspende entonces toda filosofía de la historia y le restituye la dignidad perdida a la política, en la medida en que la vuelve a pensar como lucha y antagonismo, pero no habilitada por la lógica estratégica de un conflicto central, mediada por las lógicas de la pertenencia y de la identidad, sino abierta al conatus de la existencia, aunque no abundan en Lezra las referencias a Spinoza (salvo la contra-lectura que este realiza de la famosa tesis: determinatio est negatio). Un conatus que, como insiste Deleuze en su lectura de Lucrecio ${ }^{11}$, apunta al clinamen como perseverancia y desasosiego. En ese clinamen yace no solo la posibilidad de una cosmología o una física de los cuerpos, sino de una política que se resiste a su conjugación totalizante. Es en este horizonte, amplio y complejo, donde la necrofilología desactiva la tradición e interrumpe la traducción como lógica de la equivalencia generalizada, y donde el republicanismo aparece como posibilidad de un habitar "sin miedo a la muerte" ("nada es pues la muerte y en nada nos afecta").

Pero también aquí es donde el clinamen supone una teoría de la afección y de la contingencia que rompe con el ego familístico y patriarcal moderno (me refiero a la recuperación elaborada por Lezra de un Freud materialista, más allá de Lacan), rompiendo a la vez con el sujeto jurídico del contrato social y sus abstracciones derivadas de una antropología hipotética y aparentemente secularizada, pero todavía teológicamente orientada hacia una concepción salvífica de la historia. Pues es aquí donde esta concepción del clinamen permite pensar en una teoría radical de la libertad no solo como interrupción de la causalidad, sino también de la transferencia, siempre abierta a la contingencia como acontecimiento sin teología ni excepcionalidad, en una suerte de anti-schmittianismo radical avant la lettre. En otras palabras, la aproximación acá elaborada nos permite comprender los remanentes teológico-

\footnotetext{
${ }^{10}$ Por supuesto, aquí habría que pensar el lugar que Lezra le asigna a el poema de Lucrecio, en la constitución de una república salvaje, materialista, en cuanto ese poema tematiza el azar y el clinamen, el golpe y la caída, en una suerte de "in-familiaridad" que resultaría interesante cruzar con las aprensiones de Derrida frente a la lectura heideggeriana de Georg Trakl. Véase Derrida, 2018c. Y frente al lugar pedagógico y alegórico que el poema, en general, ha cumplido para lo que, con Philippe Lacoue-Labarthe, Ilamaríamos el nacional-esteticismo moderno, en Heidegger y más allá, sobre todo, en nuestras "jóvenes repúblicas criollas" imaginadas por la Silva de Bello.

${ }^{11}$ Hipótesis sostenida por Warren Montag (2016).
} 
políticos en el pensamiento contemporáneo asociado con la cuestión de la soberanía y su indivisibilidad, como teoría del Estado o como ontología. Como en Bataille, no se trata de una superación de la soberanía, sino de su divisibilidad, la que comporta una compleja relación entre literatura, ritual y sacrificio.

Me gustaría terminar, por ahora, insistiendo en que no he intentado ni resumir ni producir una imagen acabada del trabajo de Lezra, sino solo acentuar una cierta insistencia republicana, que desanda la tradición y desactiva sus fundamentos, para pensar la república y sus instituciones más allá de la pretensión normativa moderna que ve en ellas la posibilidad y la resolución del sufrimiento y del terror. No hay afuera de la violencia, pues esta se muestra, como diría Nietzsche, inocente en su devenir, ya no marcada por la venganza y el resentimiento. Pero queda mucho por pensar y comentar, cuestión que excede mi cometido actual, sobre todo en los términos de una posible relación entre clinamen y libertad, materialismo y temporalidad, historia y narración, sin descontar, cuestión que nos devuelve siempre al comienzo, la necesaria pregunta por la serenidad imposible, o si se prefiere, por la derogación de la Gelassenheit heideggeriana, desde el terror de la existencia para la que no hay sosiego, pues prima el goce como violencia inocente y sin culpa (¿cabe la culpa en el átomo?). Como en una república de zombis, la republica salvaje lezrrática es aquella que no está ilusamente pacificada por las leyes, pues en ella se mantiene presente al otro como objeto de deseo y apropiación (mordisco), con la salvedad, no menos importante, de que la representación habitual de los zombis no está a la altura del problema material de los cuerpos, más bien expresa la disolución literal de la teoría moderna del sujeto y del individuo. Efectivamente, otra cosa es una república lucreciana, y de otros cuerpos habremos de proveernos.

\section{BIBLIOGRAFÍA}

Adorno, Th. (2005). Dialéctica negativa. Madrid: Akal.

Althusser, L. (1994). Écrits philosophiques et politiques, tome I. París: Éditions STOCK/IMEC.

Borges, J. L. (1994). Funes el memorioso. En Obras completas I. Buenos Aires: EMECE Editores, 1994. P. 490.

Calasso, R. (1994). La tienda del mago Röckle. En Los cuarenta y nueve escalones. Barcelona: Anagrama.

Campos Salvaterra, V. (2017). Violencia y fenomenología: Derrida, entre Husserl y Levinas. Santiago: Metales Pesados.

Cassin, B.; Apter, E.; Lezra, J.; Wood, M. (eds.) (2014). Dictionary of Untranslatables: A Philosophical Lexicon. Princeton: Princeton University Press.

Deleuze, G. (1989). Simulacro y filosofía antigua. En Lógica del sentido. Barcelona: Paidós.

Derrida, J. (2019). La vie la mort. Séminaire (1975-976). París: Seuil.

— (2018a). Theory and Practice, trad. de David Wills. Chicago: University of Chicago Press. 
- (2018b). Política y Amistad. Entrevistas con Michael Sprinter. Sobre Marx y Althusser. Madrid: Nueva Visión.

— (2018c). Geschlecht III. Sexe, race, nation, humanité. París: Seuil.

- (2017). Psyché. Invenciones del otro. Buenos Aires: La Cebra.

- (2016). Heidegger: The Question of Being and History, trad. de Geoffrey Bennington. Chicago: The University of Chicago Press, 2016.

— (2013). Heidegger: la question de l'Être et I'Histoire. Cours de l'ENS-UIm (19641965). París: Éditions Galilée.

- (2012). Espectros de Marx. El Estado de la deuda, el trabajo del duelo y la nueva internacional. Madrid: Trotta.

— (1986). Del materialismo no dialéctico. Entrevista con Kadhim Jihad. Culturas, 69, III-V.

— (1975). La diseminación. Trad. de José Martín Arancibia. Madrid: Fundamentos.

Heidegger, M. (2013). Carta sobre el humanismo, trad. de Helena Cortés y Arturo Leyte. Madrid: Alianza.

Hypollite, J. (1996). Lógica y existencia. Madrid: Herder.

Lezra, J. (2020). República salvaje. De la naturaleza de las cosas. Santiago: Ediciones Macul.

- (2018). On the Nature of Marx's Things. Translation as Necrophilology. New York: Fordham University Press.

- (2017). Untranslating Machines. A Genealogy for the Ends of Global Thought. London: Rowman \& Littlefield.

- (2012). Materialismo salvaje. La ética del terror y la república moderna. Trad. de Javier Rodríguez Fernández. Madrid: Biblioteca Nueva.

- (2010). Wild Materialism. The Ethic of Terror and the Modern Republic. New York: Fordham University Press.

Markovits, F. (1975). Marx en el jardín de Epicuro. Barcelona: Editorial Madrágora.

Martínez Marzoa, F. (2018). La filosofía de "El capital". Madrid: Abada.

Marx, K. (1975). El capital, vol. I, libro I. Trad. de Pedro Scarón. Ciudad de México: Siglo XXI.

- (1971). Diferencia de la filosofía de la naturaleza en Demócrito y en Epicuro. Madrid: Editorial Ayuso.

Montag, W. (2016). From Clinamen to Conatus: Deleuze, Lucretius, Spinoza. En J. Lezra y L. Blake (coords.). Lucretius and Modernity. Epicurean Encounters Across Time and Discipline. New York: Pelgrave Macmillan, 2016, pp. 163-172.

Nancy, J.-L. (2009). La verdad de la democracia. Buenos Aires: Amorrortu. 
Readings, B. (1997). The University in Ruins. Cambridge: Harvard University Press.

Schürmann, R. (2017). El principio de anarquía. Heidegger y la cuestión del actuar. Madrid: Arena Libros.

Villalobos-Ruminott, S. (2015). El poema de la universidad. Nihilismo e infrapolítica. Transmodernity: Journal of Peripheral Cultural Production of the Luso-Hispanic World, 5/1, 106-122. También en: https://escholarship.org/uc/item/3475x32f 